\title{
Microbial Content of "Bowl Water" Used for Communal Handwashing in Preschools within Accra Metropolis, Ghana
}

\author{
Patience B. Tetteh-Quarcoo, ${ }^{1}$ Isaac Anim-Baidoo, ${ }^{2}$ Simon Kwaku Attah, \\ Bawa Abdul-Latif Baako, ${ }^{2}$ Japheth A. Opintan, ${ }^{1}$ Andrew A. Minamor, ${ }^{3}$ \\ Mubarak Abdul-Rahman, ${ }^{4}$ and Patrick F. Ayeh-Kumi ${ }^{1,2}$ \\ ${ }^{1}$ Department of Medical Microbiology, School of Biomedical and Allied Health Sciences, University of Ghana, Accra, Ghana \\ ${ }^{2}$ Department of Medical Laboratory Science, School of Biomedical and Allied Health Sciences, University of Ghana, Accra, Ghana \\ ${ }^{3}$ Department of Science Laboratory Technology, Accra Polytechnic, Accra, Ghana \\ ${ }^{4}$ Department of Immunology, School of Biomedical and Allied Health Sciences, University of Ghana, Accra, Ghana
}

Correspondence should be addressed to Patience B. Tetteh-Quarcoo; patborket2002@yahoo.com

Received 31 May 2016; Accepted 10 July 2016

Academic Editor: Karl Drlica

Copyright (C) 2016 Patience B. Tetteh-Quarcoo et al. This is an open access article distributed under the Creative Commons Attribution License, which permits unrestricted use, distribution, and reproduction in any medium, provided the original work is properly cited.

\begin{abstract}
Objective. This study aimed at determining the microbial content of "bowl water" used for communal handwashing in preschools within the Accra Metropolis. Method. Six (6) preschools in the Accra Metropolis were involved in the study. Water samples and swabs from the hands of the preschool children were collected. The samples were analysed and tested for bacteria, fungi, parasites, and rotavirus. Results. Eight different bacteria, two different parasites, and a fungus were isolated while no rotavirus was detected. Unlike the rest of the microbes, bacterial isolates were found among samples from all the schools, with Staphylococcus species being the most prevalent (40.9\%). Out of the three schools that had parasites in their water, two of them had Cryptosporidium parvum. The fungus isolated from two out of the six schools was Aspergillus niger. All bacteria isolated were found to be resistant to cotrimoxazole, ciprofloxacin, and ampicillin and susceptible to amikacin and levofloxacin. Conclusion. Although handwashing has the ability to get rid of microbes, communal handwashing practices using water in bowls could be considered a possible transmission route and may be of public concern.
\end{abstract}

\section{Introduction}

Provision of a bowl of water for handwashing in preschools is an intervention by childcare facilities in Ghana, to maintain hygienic practices and prevent transmission of microbes. In the year 2005, the Ghana School Feeding Programme (GSFP) was implemented as one of the most important social interventions by the government, to help boost public basic school enrolments [1]. The programme offers one meal each day for all government preschoolers and primary school children. This provision is to reduce hunger and malnutrition, increase school enrolment and attendance, and stimulate local food production. Similarly, many privately owned preschools provide meals for their pupils. This has therefore necessitated the provision of water for handwashing before and after meals.
"Bowl water" (water in a basin/bowl) has been adapted to serve this purpose whenever the flow of running tap water is interrupted.

Handwashing has been regarded as a significant preventive measure against diarrhoeal diseases [2]. It is an effective [2], feasible [2-5], and cost-effective [6] means of preventing gastroenteric infection worldwide. Recently, there has been growing awareness of its importance not only as a diarrhoeal disease preventive measure [2,7], but also as part of a wider public health effort to reduce the disease burden of acute respiratory infections worldwide [2, 8-10]. The importance of handwashing has also been underlined in a recent review of measures to control the spread of pandemic influenza [11]. The two leading causes of disease burden globally, respiratory infections and diarrhoeal diseases, are responsible for half 
of all childhood deaths each year [12]. Therefore, good and adequate handwashing practice is a prerequisite to disease control and child's survival $[2,13]$.

With reference to an appropriate handwashing procedure [14], communal handwashing from a bowl of water is not the best practice. A handwashing facility, even with soap, on a communal basis, where the same water is used by more than one person, does not constitute an adequate handwashing facility $[15,16]$. This practice, especially when the water in the bowl is not changed frequently, could increase the exchange of microbes among the children when the goal is to get rid of them. Therefore, this study aimed at determining the microbial content of "bowl water" used for handwashing in preschools within Accra Metropolis. This will help in the understanding of the possible role that "bowl water" could play in the transmission of infectious agents. It will also help appreciate whether, in the absence of flowing tap water, washing from a bowl of water could serve as an alternative way of getting rid of most microbes among children.

\section{Methods}

2.1. Study Site and Sample Collection. Preschools within Accra, the capital of Ghana, that either are under the Ghana School Feeding Programme or are private schools that provide meals for children were selected for the current study. To maintain anonymous identity of the schools and confidentiality, the schools were coded as SA, SB, SC, SD, SE, and SF. Sterile plastic bottles were used to aseptically collect $1000 \mathrm{~mL}$ each of water samples used for handwashing and rinsing. Three water samples were taken from each school; one sample was taken from their main source, such as water storage tanks, commonly called "poly tank," tap, and well, and labelled as "source." Another sample was taken from the basins containing water for handwashing and labelled as "soapy water" and a third sample was taken from the basin containing water for rinsing and labelled as "rinse." After a brief interview using a questionnaire, swabs were obtained from three randomly selected pupils from each school, before they washed their hands and after handwashing. The collected samples (both the water and the swabs) were transported on ice packs, to the laboratories at the Departments of Medical Microbiology and Medical Laboratory Sciences, all of the School of Biomedical and Allied Health Sciences, University of Ghana, for examination.

2.2. Parasitological Examination. One hundred millilitres $(100 \mathrm{~mL})$ of each water sample was centrifuged at $5000 \mathrm{rpm}$ for 10 minutes. The supernatant was discarded and the remaining sediments were resuspended and examined by the direct wet mount and concentration techniques $[17,18]$. Briefly, a drop of the sediment was placed on two clean grease-free microscope slides. To one, a drop of iodine was added and both were covered with coverslips. Each slide was then examined under a light microscope for the presence of life forms of protozoans and helminths. Formolether concentration method was employed on the rest of the sediments $[17,18]$. After concentration, three slides were made from each resuspended sediment. Two out of the three slides were stained, one with iodine and the other with modified Z-N stain, and the third was examined directly as wet mount using standard procedures [19].

\subsection{Isolation, Enumeration, and Identification of Bacteria} and Fungi. The water samples were well mixed and using disposable sterile loops ( $2 \mathrm{~mm}$ inside diameter) each of the samples was inoculated onto MacConkey agar (MA) and blood agar (BA) (Oxoid Ltd., Basingstoke, UK). The swabs were also inoculated (directly) onto MA and BA. The plates were incubated at $37^{\circ} \mathrm{C}$ for 24 hours. The number of colonies seen was counted using a colony counter and recorded as colony forming unit per gram ( $\mathrm{cfu} / \mathrm{g}$ ) for swabs and colony forming unit per millilitre $(\mathrm{cfu} / \mathrm{mL})$ for water samples. Bacteria colonies were further subcultured onto MA and BA, to obtain pure cultures and primary identification done using colonial morphology. Further identification was done based on a number of procedures including microscopy, Gram staining, oxidation-fermentation tests, and other biochemical tests such as urease test, catalase test, citrate utilization test, indole test, and triple sugar iron test [20-23].

Similarly, the water samples and swabs were inoculated on Sabouraud agar (Oxoid Ltd., Basingstoke, UK) for fungal growth and subsequent identification using standard protocol [19].

2.4. Susceptibility Testing of Bacteria. Susceptibility test for identified bacteria was determined using a modified form of the Kirby Bauer method. The antimicrobials tested with their disk concentrations in micrograms $(\mu \mathrm{g})$ were gentamicin (15), amikacin (30), tetracycline (30), cotrimoxazole (25), cefotaxime (30), meropenem (10), ampicillin (10), ceftriaxone (30), chloramphenicol (30), cefuroxime (30), levofloxacin (5), and ciprofloxacin (5) (Oxoid Ltd., Basingstoke, UK). These antimicrobials are among the common drugs found on the Ghanaian market. Briefly, on the procedure for antibiotic susceptibility testing, the test organism was emulsified in peptone water until the suspension was comparable with 0.5 McFarland's standard. A sterile cotton swab was dipped into the suspension and drained by pressing the swab against the inside of the bottle. The swab was then used to streak the entire surface of a Mueller-Hinton agar plate (Oxoid Ltd., Basingstoke, UK). The moisture was allowed to be absorbed for at least 15 minutes and sterile forceps were used to apply the antibiotic discs to the surface of the agar plates. The plate was kept at $4^{\circ} \mathrm{C}$ for $4-6$ hours, so that the antibiotic can diffuse on the agar media after which it was incubated at $37^{\circ} \mathrm{C}$ for 18-24 hours. Zone diameters around the antibiotic discs were measured and later classified as susceptible or resistant based on the Clinical Laboratory Standards Institute (CLSI) criteria [24]. Control strain used for the susceptibility test was Escherichia coli NCTC 10418.

2.5. Virological Examination. The water samples were tested for rotavirus using the ProSpecT ${ }^{\mathrm{TM}}$ Rotavirus ELISA kit (Oxoid Ltd., UK). The process was carried out using the protocol designed by the manufacturer (Oxoid Ltd., UK). 


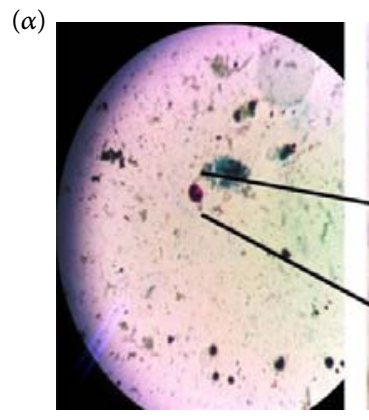

(a)

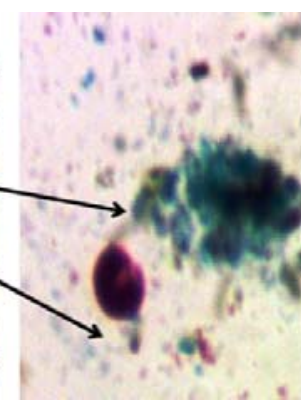

(b)

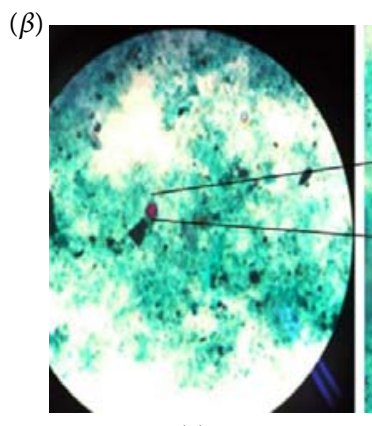

(a)

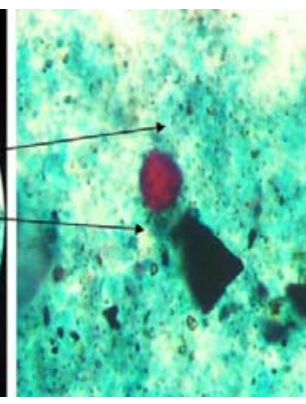

(b)

FIGURE 1: Modified ZN stained slides of parasites identified. ( $\alpha$ ) Oocysts of Cyclospora cayetanensis. ( $\beta$ ) Oocyst of Cryptosporidium parvum. (a) represents magnification of $\times 1000$ while (b) is a zoom-in of the oocyst.

TABLE 1: Demographic data of schools recruited in the study.

\begin{tabular}{|c|c|c|c|}
\hline School ID & Location & Ownership & Type of school \\
\hline SA & Arena & Government & $\begin{array}{l}\text { Preschool with } \\
\text { primary level }\end{array}$ \\
\hline SB & Arena & Private & $\begin{array}{c}\text { Preschool up to JHS } \\
\text { level }\end{array}$ \\
\hline SC & Chorkor & Private & Preschool only \\
\hline SD & Chorkor & Private & $\begin{array}{l}\text { Preschool with } \\
\text { primary level }\end{array}$ \\
\hline SE & Mamprobi & Private & $\begin{array}{l}\text { Preschool with } \\
\text { primary level }\end{array}$ \\
\hline SF & Korle Gonno & Private & $\begin{array}{l}\text { Preschool with } \\
\text { primary level }\end{array}$ \\
\hline
\end{tabular}

To ensure quality and accurate results, positive and negative controls were run for each test.

\section{Results}

A total of 6 preschools were involved in the study. Three water samples and six swabs were obtained from each preschool making a total of 54 samples for the investigation. Five (83\%) of the preschools were privately owned while only one was government owned (Table 1). The schools had different stages, ranging from preschool to junior high school (JHS) (Table 1).

Parasitological investigations identified two different parasites (Table 2). Cryptosporidium parvum and Cyclospora cayetanensis were both found in the rinsing water of school SB and the soapy water of school SD. Meanwhile, Cryptosporidium parvum was also found in the main water source of school SC (Figure 1).

Bacteriological investigations identified eight (8) different bacteria in the different water types (Table 2). The bacteria isolates were in the following proportions: Staphylococcus species (40.9\%), Escherichia coli (13.6\%), Citrobacter species (13.6\%), Klebsiella species (4.6\%), Proteus mirabilis (2.3\%), Klebsiella pneumoniae (9.1\%), Salmonella species (9.1\%), and Klebsiella oxytoca (6.8\%). Staphylococcus specieswas the most common isolate from all the preschools except for SF. Salmonella species was isolated from four different preschools, while Escherichia coli, Citrobacter species, and Klebsiella pneumoniae were identified in three different schools. Klebsiella oxytoca and Klebsiella species were identified in two preschools and Proteus mirabilis was isolated from only one preschool.

Examination of the swabs showed that Staphylococcus species was present before handwashing and after handwashing. Escherichia coli, Citrobacter species, Salmonella species, Klebsiella pneumoniae, and Klebsiella oxytoca were only isolated from swabs obtained after handwashing (Table 2). Notably, just a few colonies were observed for most of the bacterial isolates, for the different sources of water and hand swabs. The ranges of colony forming units of the isolates from various samples are as follows: Staphylococcus spp. $\left(1.2 \times 10^{2}-\right.$ $\left.1.2 \times 10^{3}\right)$, Salmonella spp. $\left(1.0 \times 10^{1}-3.2 \times 10^{1}\right)$, E. coli $(1.1$ $\left.\times 10^{1}-1.7 \times 10^{1}\right)$, Citrobacter spp. $\left(1.4 \times 10^{1}-4.2 \times 10^{1}\right), K$. pneumonia $\left(1.5 \times 10^{2}-7.0 \times 10^{2}\right)$, K. oxytoca $\left(2.0 \times 10^{2}-4.2 \times\right.$ $\left.10^{2}\right)$, Klebsiella spp. $\left(1.0 \times 10^{2}-3.3 \times 10^{2}\right)$, and P. mirabilis $(1.0 \times$ $\left.10^{3}-1.5 \times 10^{4}\right)$. Apart from Staphylococcus spp. and P. mirabilis, all the remaining bacteria recorded cfu below $10^{3}$ (Table 3).

The isolated Gram negative bacteria were tested against twelve selected antimicrobial agents. All the organisms tested $(6 / 6,100 \%)$ were resistant to cotrimoxazole, ampicillin, and ciprofloxacin while they were susceptible (100\%) to amikacin and levofloxacin. The organisms showed varying percentage resistance to the remaining antibiotics (Figure 2). Notably, for gentamicin, resistance was seen among Salmonella species, Klebsiella pneumoniae, and Klebsiella oxytoca. All bacteria, except for Proteus mirabilis and Escherichia coli,were resistant to cefuroxime. Similarly, resistance to chloramphenicol was observed in all the bacteria tested except for Citrobacter speciesand Escherichia coli. Meanwhile, the only organism susceptible to tetracycline was Escherichia coli.

From the fungal studies, Aspergillus niger was identified from hand swabs of school children from schools SB and SC before and after handwashing. The same fungal species was also found in the soapy water of school SB (Figure 3).

The rotavirus screening did not detect the presence of the virus in any of the water samples collected from the schools, as well as the swabs obtained from the hands of the children (Table 2). Other viruses could not be investigated due to inadequate resources. 
TABLE 2: Microbial contamination of different sources of bowl water and hands of children.

\begin{tabular}{|c|c|c|c|c|c|}
\hline Microorganism & $\begin{array}{c}\text { Main, } n(\%) \\
N=18 \\
\end{array}$ & $\begin{array}{c}\text { Soapy, } n(\%) \\
N=18\end{array}$ & $\begin{array}{c}\text { Rinse, } n(\%) \\
N=18\end{array}$ & $\begin{array}{l}\text { Hand before washing, } n(\%) \\
\qquad N=36\end{array}$ & $\begin{array}{l}\text { Hand after washing, } n(\%) \\
\qquad N=36\end{array}$ \\
\hline \multicolumn{6}{|l|}{ Parasites } \\
\hline C. parvum & $1(12.5)$ & $2(7.1)$ & $2(9.1)$ & $0(0)$ & $0(0)$ \\
\hline C. cayetanensis & $0(0.0)$ & $2(7.1)$ & $2(9.1)$ & $0(0)$ & $0(0)$ \\
\hline \multicolumn{6}{|l|}{ Bacteria } \\
\hline Staphylococcus spp. & $2(25.0)$ & $5(18.0)$ & $5(22.7)$ & $12(85.7)$ & $15(31.2)$ \\
\hline Salmonella spp. & $0(0.0)$ & $4(14.3)$ & $2(9.1)$ & $0(0.0)$ & $9(18.8)$ \\
\hline E. coli & $2(25.0)$ & $3(10.7)$ & $3(13.6)$ & $0(0.0)$ & $8(16.7)$ \\
\hline Citrobacter spp. & $1(12.5)$ & $3(10.7)$ & $3(13.6)$ & $0(0.0)$ & $6(12.5)$ \\
\hline K. pneumonia & $1(12.5)$ & $3(10.7)$ & $2(9.1)$ & $0(0.0)$ & \\
\hline K. oxytoca & $0(0.0)$ & $2(7.1)$ & $2(9.1)$ & $0(0.0)$ & $4(8.3)$ \\
\hline Klebsiella spp. & $1(12.5)$ & $2(7.1)$ & $1(4.6)$ & $0(0.0)$ & $4(8.3)$ \\
\hline P. mirabilis & $0(0.0)$ & $1(3.6)$ & $0(0.0)$ & $0(0.0)$ & $0(0.0)$ \\
\hline \multicolumn{6}{|l|}{ Fungus } \\
\hline A. niger & $0(0.0)$ & $1(3.6)$ & $0(0.0)$ & $2(14.3)$ & $2(4.2)$ \\
\hline \multicolumn{6}{|l|}{ Virus } \\
\hline Rotavirus & $0(0.0)$ & $0(0.0)$ & $0(0.0)$ & $0(0.0)$ & $0(0.0)$ \\
\hline
\end{tabular}

$N$ represents the total number of samples used. $n$ represents number of particular microbes identified.

TABLE 3: Bacteria colony count of water samples (cfu/mL) and hand-swab samples (cfu/g).

\begin{tabular}{|c|c|c|c|c|c|}
\hline \multirow{2}{*}{ Bacterial isolates } & \multicolumn{3}{|c|}{ Water sources } & \multicolumn{2}{|c|}{ Swabs } \\
\hline & Main & Soapy & Rinse & Hand before washing & Hand after washing \\
\hline Staphylococcus spp. & $1.2 \times 10^{3}$ & $1.5 \times 10^{3}$ & $1.2 \times 10^{3}$ & $1.8 \times 10^{2}$ & $1.2 \times 10^{2}$ \\
\hline Salmonella spp. & $3.0 \times 10^{1}$ & $3.2 \times 10^{1}$ & $3.0 \times 10^{1}$ & $1.0 \times 10^{1}$ & $1.2 \times 10^{1}$ \\
\hline E. coli & $1.1 \times 10^{1}$ & $1.3 \times 10^{1}$ & $1.1 \times 10^{1}$ & $1.7 \times 10^{1}$ & $1.5 \times 10^{1}$ \\
\hline Citrobacter spp. & $3.0 \times 10^{1}$ & $4.2 \times 10^{1}$ & $1.4 \times 10^{1}$ & $3.7 \times 10^{1}$ & $3.0 \times 10^{1}$ \\
\hline K. pneumonia & $1.8 \times 10^{2}$ & $2.3 \times 10^{2}$ & $1.5 \times 10^{2}$ & $7.0 \times 10^{2}$ & $1.8 \times 10^{2}$ \\
\hline K. oxytoca & $2.3 \times 10^{2}$ & $2.2 \times 10^{2}$ & $2.0 \times 10^{2}$ & $4.0 \times 10^{2}$ & $4.2 \times 10^{2}$ \\
\hline Klebsiella spp. & $2.0 \times 10^{2}$ & $1.3 \times 10^{2}$ & $1.0 \times 10^{2}$ & $3.3 \times 10^{2}$ & $3.3 \times 10^{2}$ \\
\hline P. mirabilis & $1.5 \times 10^{3}$ & $1.0 \times 10^{3}$ & $3.0 \times 10^{3}$ & $1.5 \times 10^{4}$ & $4.3 \times 10^{3}$ \\
\hline
\end{tabular}

\section{Discussion}

Bacteria isolates from the current study include Salmonella species, Citrobacter species, Escherichia coli, Proteus mirabilis, Klebsiella pneumoniae, and Klebsiella oxytoca. Most of these organisms have also been isolated from a work done by Tetteh-Quarcoo et al., when they investigated microbial carriage of cockroaches within the same geographical location as this study [25]. This shows likelihood of these bacteria species circulating within the metropolis. A recent study conducted by Ayeh-Kumi et al., on tiger nuts which were claimed to have been washed and sold in locations including that of the current study, also found bacterial isolates, including Klebsiella oxytoca, suggesting the association of this particular bacterium with water used within the metropolis [26]. Most of the bacteria isolated in this study are pathogenic or potentially pathogenic and are therefore of public health significance, especially when in connection with preschool children. For example, Klebsiella pneumo niae causes pneumonia, urinary tract infections, and wound infections [23, 24]. Studies have shown that individuals with recurrent infections and those with structural abnormalities of the urinary tract have an increased frequency of infection caused by bacteria such as Klebsiella oxytoca $[27,28]$.

The isolation of Escherichia coli shows that washing with bowl-water is a possible source of transmitting this bacterium, which causes acute diarrhoea, especially in children [29]. Although Escherichia coli is part of the normal flora of the intestinal tract, certain strains can cause moderate to severe gastroenteritis in adults and children [29]. Salmonella species and Escherichia coli were isolated from even the source where the water used for handwashing was fetched. This is not surprising, since even sachet water, regarded as more purified, has been found to contain high levels of bacteria [30]. Almost all the bacteria isolated in this study are mostly responsible for enteric diseases in young children. 


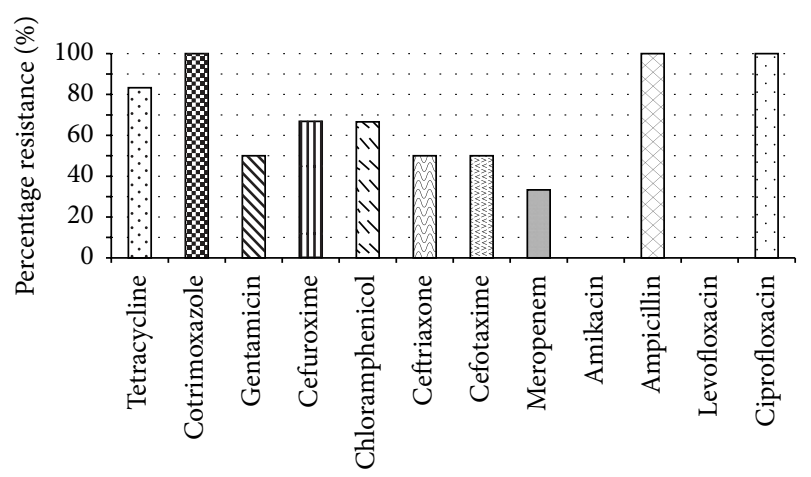

Antibiotics

FIGURE 2: Percentage resistance of antibiotics tested. Six out of the eight isolates tested, namely, Salmonella species, Citrobacter species, Escherichia coli, Proteus mirabilis, Klebsiella pneumoniae, and Klebsiella oxytoca. The values of diameter $(\mathrm{mm})$ measurement that were considered sensitive are as follows: tetracycline $\geq 26$, cefotaxime $\geq 26$, cotrimoxazole $\geq 24$, ampicillin $\geq 17$, gentamicin $\geq 20$, ciprofloxacin $\geq 21$, cefuroxime $\geq 18$, meropenem $\geq 16$, amikacin $\geq$ 20 , chloramphenicol $\geq 30$, ceftriaxone $\geq 21$, and levofloxacin $\geq 17$.

All the same, the bacteriological methods used in this study provided not much quantification of bacterial load, unlike a study by Hoque et al. [31]. Staphylococcus species was very common in each of the preschools. Infections from this organism occur when staphylococci enter the body through breaks, cuts, and abrasions in the skin or mucous membranes. Hence, children who have openings such as cuts and abrasions of the skin have a high risk of getting infection caused by this organism when they use such handwashing facilities. Isolation of Citrobacter species is a notable observation, since Citrobacter infections can be community acquired. Citrobacter species also cause meningitis, septicaemia, and pulmonary infections in neonates and young children. Most of these organisms were enteric bacteria which possibly found their way through accidentally, due to poor hygiene, suggestive of faecal contamination.

Observation from the antibiotic resistance testing of the current study conforms with the observation by TettehQuarcoo et al. [25] and reemphasizes the assertion that some antibiotics such as cotrimoxazole, ampicillin, and ciprofloxacin have been on the Ghanaian market for a long time and therefore might have been subjected to indiscriminate use or abuse leading to the high levels of resistance recorded [32,33]. Although ciprofloxacin and levofloxacin are both from the same class of antibiotics (fluoroquinolones), there was a notable difference in their performance against the bacteria isolates tested. This observation could be due to the probable indiscriminate use of ciprofloxacin in Ghana, since it is readily available compared to levofloxacin. Citrobacter species was found to be resistant to five out of the 12 antibiotics tested. In spite of this, Shih et al. [34] found that the combination of a beta-lactam and an aminoglycoside had better therapeutic results than a single agent alone for Citrobacter bacteremia; hence, children who acquire infection through handwashing can be treated using this recommendation. Staphylococcus species were isolated from swabs before handwashing and after handwashing. Escherichia coli, Citrobacter species, Salmonella species, Klebsiella pneumoniae, and Klebsiella oxytoca were only isolated from swabs obtained after handwashing. Another study also isolated Staphylococcus species, Escherichia coli, and Klebsiella from the hands of preschool nurses [35]. Most of the isolates found on the hand swabs were from the "after handwashing" samples and therefore it is suggested that the children might have picked the bacteria during handwashing process. All the same, it is noteworthy that just a few colonies were counted for most of the bacteria isolates. This implies that although pathogenic bacteria were among the agents isolated, infection from these organisms might mostly be manifested in immunocompromised children who use this handwashing process.

Cryptosporidium parvum and Cyclospora cayetanensis were present in some of the water samples used for handwashing in the preschools. These organisms are potential pathogens associated with water related diarrhoea outbreaks in healthy people and have devastating presentations in the immunocompromised individuals, particularly children [36]. The result of this study supports the findings of ObiriDanso et al., when they carried out a study to determine the microbial quality of water on the streets of Kumasi [37]. These organisms are also notable for the stability of their oocysts in the environment [38]. Hence, the finding of these parasites in the "bowl water" used for handwashing by preschool children is of public health importance.

The current study identified Aspergillus niger from the hands of school children before and after handwashing and also from soapy water used for handwashing. This emphasizes the ubiquitous nature of this mould and its association with water $[39,40]$. In a study, different species of fungi were recovered from Dead Sea water, many of which belonged to nonhalophilic terrestrial species, known for their diverse distribution [39]. Examples of these species include Aspergillus niger and Cladosporium cladosporioides [39]. In spite of their widespread occurrence, little attention has been given to the presence of fungi and their significance in preschool environments. The observation of Aspergillus niger from water samples used for handwashing suggests that the communal handwashing facility could be considered a possible transmission route forthis fungal species. Although Aspergillus species cause significant pulmonary infections, Aspergillus niger has rarely been reported as a cause of invasive pulmonary aspergillosis [40]. Therefore, identifying only this species in the study lowers the possibility of significant pulmonary infections in the school children, acquired through the handwashing process.

In relation to rotavirus, all the test results were negative. In Ghana, almost half of the diarrhoeal disease hospitalization cases of children under 5 years of age are caused by rotavirus [41]; hence, this virus was included in the microbes under investigation in the current study. The absence of this virus in the bowl water and hands of school children is a positive and a comforting finding. In spite of this, the absence of detection of rotavirus may be a reflection of the sample size used in the current study or the season when the samples were collected. 


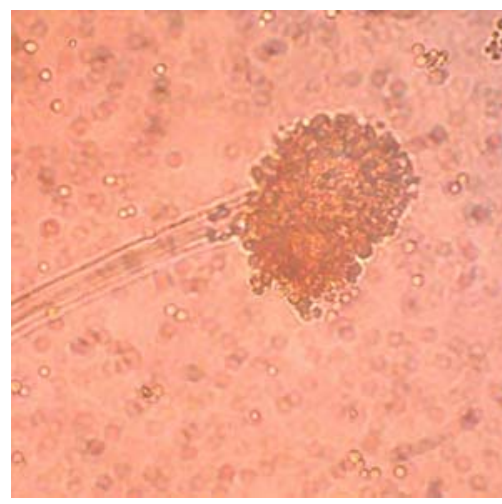

(a)

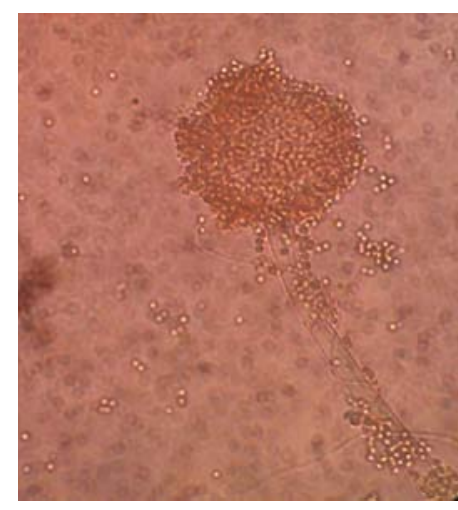

(b)

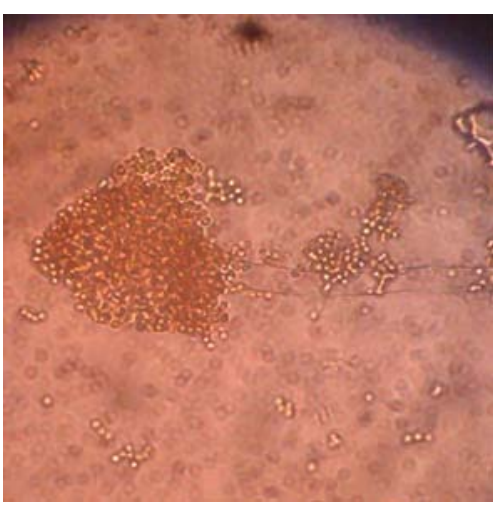

(c)

FIGURE 3: A wet preparation of Aspergillus niger showing "sporing structure." ((a) and (b)) From hands of school children, (c) from soapy water.

It is therefore important not to infer that all handwashing bowls are free of rotavirus.

\section{Conclusion}

In the absence of running tap water in most locations, provision of "bowl water" for handwashing in preschools has been a common practice within the Accra Metropolis. The current study demonstrated the presence of microbes of faecal and zoonotic origin in some of the swabs and water samples examined (except for rotavirus). This can be of public health concern as some of the organisms identified can cause diseases especially in immunocompromised individuals and young children. Although handwashing has the ability to get rid of some microbes, this communal handwashing practice using water in a bowl could be considered a possible transmission route and may be of public concern. Even though pathogenic bacteria were isolated, the colony forming units for most of them were low. In spite of the low cfu and nondetectable rotavirus content of the water samples in the current study, adapting an improvised running water system will be an improvement. Therefore, adapting a system like the "tippy-tap" which is already practiced in some schools in Ghana and has proven to deliver promising results since its introduction in some parts of Uganda [42] is highly recommended.

$\begin{array}{ll}\text { Abbreviations } & \\ \text { K. oxytoca: } & \text { Klebsiella oxytoca } \\ \text { E. coli: } & \text { Escherichia coli } \\ \text { Citrobacter spp.: } & \text { Citrobacter species } \\ \text { P. mirabilis: } & \text { Proteus mirabilis } \\ \text { C. parvum: } & \text { Cryptosporidium parvum } \\ \text { C. cayetanensis: } & \text { Cyclospora cayetanensis } \\ \text { Z-N: } & \text { Ziehl-Neelsen } \\ \text { MA: } & \text { MacConkey agar } \\ \text { BA: } & \text { Blood agar } \\ \text { WHO: } & \text { World Health Organization }\end{array}$

GSFP: Ghana School Feeding Programme

CLSI: Clinical and Laboratory Standards Institute

CFU: Colony forming unit

JHS: Junior High School.

\section{Competing Interests}

The authors declare that they have no competing interests.

\section{Authors' Contributions}

Patience B. Tetteh-Quarcoo conceived and designed the experiments. Andrew A. Minamor, Bawa Abdul-Latif Baako, Japheth A. Opintan, and Patience B. Tetteh-Quarcoo participated in collection and analyses of the data and drafting of the paper. Simon Kwaku Attah, Andrew A. Minamor, Isaac Anim-Baidoo, Bawa Abdul-Latif Baako, and Mubarak Abdul-Rahman contributed to interpretation of the data. Patience B. Tetteh-Quarcoo, Isaac Anim-Baidoo, and Patrick F. Ayeh-Kumi jointly developed the structure and arguments for the paper. Isaac Anim-Baidoo, Japheth A. Opintan, and Patrick F. Ayeh-Kumi made critical revisions and approved the final version. All authors read and approved the final paper.

\section{Acknowledgments}

The authors wish to acknowledge all schools and children who participated in the study. Rotavirus investigation was supported by the virology unit of the Department of Medical Microbiology. The authors therefore wish to thank all the staff of the Departments of Medical Laboratory Sciences and Medical Microbiology (all of SBAHS) for their help.

\section{References}

[1] GSFP, "Ghana's School Feeding Program," 2013, https://www .modernghana.com/news/351140/ghana-school-feeding-programme-under-review.html. 
[2] V. Curtis and S. Cairncross, "Effect of washing hands with soap on diarrhoea risk in the community: a systematic review," Lancet Infectious Diseases, vol. 3, no. 5, pp. 275-281, 2003.

[3] M. U. Khan, "Interruption of shigellosis by hand washing," Transactions of the Royal Society of Tropical Medicine and Hygiene, vol. 76, no. 2, pp. 164-168, 1982.

[4] B. F. Stanton and J. D. Clemens, "An educational intervention for altering water-sanitation behaviors to reduce childhood diarrhea in urban Bangladesh. II. A randomized trial to assess the impact of the intervention on hygienic behaviors and rates of diarrhea," American Journal of Epidemiology, vol. 125, no. 2, pp. 292-301, 1987.

[5] J. V. Pinfold and N. J. Horan, "Measuring the effect of a hygiene behaviour intervention by indicators of behaviour and diarrhoeal disease," Transactions of the Royal Society of Tropical Medicine and Hygiene, vol. 90, no. 4, pp. 366-371, 1996.

[6] J. Borghi, L. Guinness, J. Ouedraogo, and V. Curtis, "Is hygiene promotion cost-effective? A case study in Burkina Faso," Tropical Medicine \& International Health, vol. 7, no. 11, pp. 960-969, 2002.

[7] L. Fewtrell, R. B. Kaufmann, D. Kay, W. Enanoria, L. Haller, and J. M. Colford Jr., "Water, sanitation, and hygiene interventions to reduce diarrhoea in less developed countries: a systematic review and meta-analysis," The Lancet Infectious Diseases, vol. 5, no. 1, pp. 42-52, 2005.

[8] L. Roberts, W. Smith, L. Jorm, M. Patel, R. M. Douglas, and C. McGilchrist, "Effect of infection control measures on the frequency of upper respiratory infection in child care: a randomized, controlled trial," Pediatrics, vol. 105, no. 4 I, pp. 738-742, 2000.

[9] K. J. Ryan and C. G. Ray, Eds., Sherris Medical Microbiology, McGraw Hill, New York, NY, USA, 4th edition, 2004.

[10] S. P. Luby, M. Agboatwalla, D. R. Feikin et al., "Effect of handwashing on child health: a randomised controlled trial," The Lancet, vol. 366, no. 9481, pp. 225-233, 2005.

[11] D. Bell, A. Nicoll, K. Fukuda et al., "Nonpharmaceutical interventions for pandemic influenza, national and community measures," Emerging Infectious Diseases, vol. 12, no. 1, pp. 88-94, 2006.

[12] C. J. L. Murray and A. D. Lopez, "Global mortality, disability, and the contribution of risk factors: global burden of disease study," The Lancet, vol. 349, no. 9063, pp. 1436-1442, 1997.

[13] United Kingdom Department for Education and Skills, "Full day care: national standards for under 8 s day care and child minding," Department for Education and Skills, Great Britain, UK, 2001, http://lx.iriss.org.uk/sites/default/files/resources/ script_-_hand_hygiene.pdf.

[14] L. Langeri, Hygiene Education and Environmental Sanitation in Schools in Vietnam, World Health Organisation, Geneva, Switzerland, 1983.

[15] Centers for Disease Control and Prevention, "Appendix C: hand washing recommendation to reduce disease transmission from animals in public setting," Morbidity and Mortality Weekly Report, vol. 56, no. 5, pp. 16-17, 2007.

[16] B. E. Scott, D. W. Lawson, and V. Curtis, "Hard to handle: understanding mothers' handwashing behaviour in Ghana," Health Policy and Planning, vol. 22, no. 4, pp. 216-224, 2007.

[17] M. Cheesbrough, District Laboratory Practice in Tropical Countries, Cambridge University Press, Cambridge, UK, 2nd edition, 2005.
[18] J. Schwartzbrod, Methods of Analysis of Helminth Eggs and Cysts in Wastewater, Sludge, Soils and Crops, University Henry Poincare, Nancy, France, 1998.

[19] CDC, "Staining procedures, Atlanta, Georgia, Centers for Disease Control and Prevention," 2014, http://dpd.cdc.gov/dpdx/ html/Frames/DiagnosticProcedures/body_dp_stoolstaining .htm.

[20] D. J. Flournoy, S. Wongpradit, and S. L. Silberg, "Facilitating identification of lactose-fermenting enterobacteriaceae on macconkey agar," Proceedings of the Oklahoma Academy of Science, vol. 70, pp. 5-8, 1990.

[21] A. W. Bauer, W. M. Kirby, J. C. Sherris, and M. Turck, "Antibiotic susceptibility testing by a standardized single disk method," American Journal of Clinical Pathology, vol. 45, no. 4, pp. 493496, 1966.

[22] National Committee for Clinical Laboratory Standards, "Performance standards for antimicrobial susceptibility testing. Fifteenth informational supplement," NCCLS Document M100S15, 2005, http://www.clsi.org/.

[23] K. Todar, "Todar's Online Textbook of Bacteriology: Streptococcus Pneumonia," 2004, http://www.textbookofbacteriology.net/S.pneumoniae.html.

[24] Clinical and Laboratory Standards Institute, "Performance standards for antimicrobial susceptibility testing," Nineteenth Informational Supplement M100-S19, Clinical and Laboratory Standards Institute, Wayne, Pa, USA, 2009.

[25] P. B. Tetteh-Quarcoo, S. E. Donkor, K. S. Attah et al., "Microbial carriage of cockroaches at a tertiary care hospital in ghana," Environmental Health Insights, vol. 7, pp. 59-66, 2013.

[26] P. F. Ayeh-Kumi, P. B. Tetteh-Quarcoo, K. O. Duedu et al., "A survey of pathogens associated with Cyperus esculentus $\mathrm{L}$ (tiger nuts) tubers sold in a Ghanaian city," BMC Research Notes, vol. 7, no. 1, article 343, 2014.

[27] R. Allan, "The etiology of urinary tract infection: traditional and emerging pathogens," American Journal of Medicine, pp. 14-19, 2002.

[28] A. C. Fluit, M. E. Jones, F.-J. Schmitz, J. Acar, R. Gupta, and J. Verhoef, "Antimicrobial resistance among urinary tract infection (UTI) isolates in Europe: results from the SENTRY Antimicrobial Surveillance Program 1997," Antonie Van Leeuwenhoek, vol. 77, no. 2, pp. 147-152, 2000.

[29] R. Bangar, B. Mamatha, and B. Indira, "A novel treatment approach towards Emerging multidrug resistant enteroaggregative Escherichia coli (eaec) causing acute/persistent diarrhoea using medicinal plant extracts," Research Journal of Pharmaceutical, Biological and Chemical Sciences, vol. 2, no. 1, pp. 15-23, 2011.

[30] D. N. A. Tagoe, H. Nyarko, S. A. Arthur, and E. Birikorang, "A study of antibiotic susceptibility pattern of bacteria isolates in sachet drinking water sold in the cape coast metropolis of Ghana," Research Journal of Microbiology, vol. 6, no. 2, pp. 153158, 2011.

[31] B. A. Hoque, D. Mahalanabis, M. J. Alam, and M. S. Islam, "Postdefecation handwashing in Bangladesh: practiceand efficiency perspectives," Public Health, vol. 109, no. 1, pp. 15-24, 1995.

[32] M. J. Newman, E. Frimpong, E. S. Donkor, J. A. Opintan, and A. Asamoah-Adu, "Resistance to antimicrobial drugs in Ghana," Infection and Drug Resistance, vol. 4, no. 1, pp. 215-220, 2011.

[33] E. S. Donkor and E. Nartey, "Nasal colonisation of drug resistant bacteria in Ghanaian children less than five years," The Internet Journal of Microbiology, vol. 5, no. 2, 2008. 
[34] C.-C. Shih, Y.-C. Chen, S.-C. Chang, K.-T. Luh, and W.-C. Hsieh, "Bacteremia due to Citrobacter species: significance of primary intra-abdominal infection," Clinical Infectious Diseases, vol. 23, no. 3, pp. 543-549, 1996.

[35] J. Olaitan and O. Adeleke, "Bacteria in day care environment," The Internet Journal of Microbiology, vol. 3, no. 1, pp. 1-5, 2006.

[36] M. Kartalija and M. A. Sande, "Diarrhea and AIDS in the era of highly active antiretroviral therapy," Clinical Infectious Diseases, vol. 28, no. 4, pp. 701-707, 1999.

[37] K. Obiri-Danso, A. Okore-Hanson, and K. Jones, "The microbiological quality of drinking water sold on the streets in Kumasi, Ghana," Letters in Applied Microbiology, vol. 37, no. 4, pp. 334339, 2003.

[38] F. A. Nime, J. D. Burek, D. L. Page, M. A. Holscher, and J. H. Yardley, "Acute enterocolitis in a human being infected with the protozoan Cryptosporidium," Gastroenterology, vol. 70, no. 4, pp. 592-598, 1976.

[39] T. I. Mbata, "Isolation of fungi in hyper saline Dead Sea water," Sudanese Journal of Public Health, vol. 3, no. 4, p. 172, 2008.

[40] A. K. Person, S. M. Chudgar, B. L. Norton, B. C. Tong, and J. E. Stout, "Aspergillus niger: an unusual cause of invasive pulmonary aspergillosis," Journal of Medical Microbiology, vol. 59, no. 7, pp. 834-838, 2010.

[41] C. C. Enweronu-Laryea, K. W. C. Sagoe, J. M. Mwenda, and G. E. Armah, "Severe acute rotavirus gastroenteritis in children less than 5 years in southern Ghana: 2006-2011," Pediatric Infectious Disease Journal, vol. 33, no. 1, supplement, pp. S9-S13, 2014.

[42] A. Biran, Enabling Technologies for Handwashing with Soap: A Case Study on the Tippy-Tap in Uganda, Global Scaling Up Handwashing Project, 2011. 

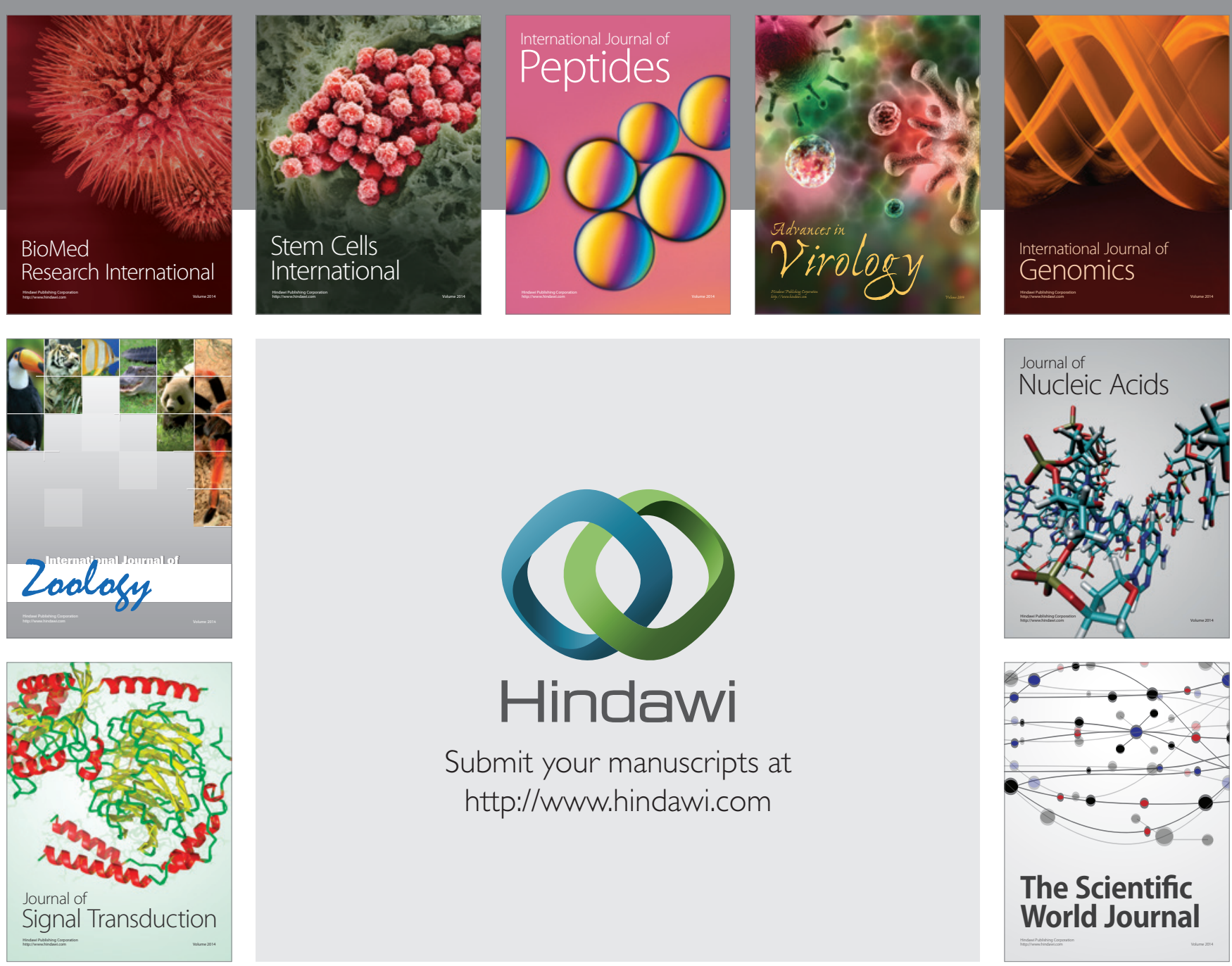

Submit your manuscripts at

http://www.hindawi.com
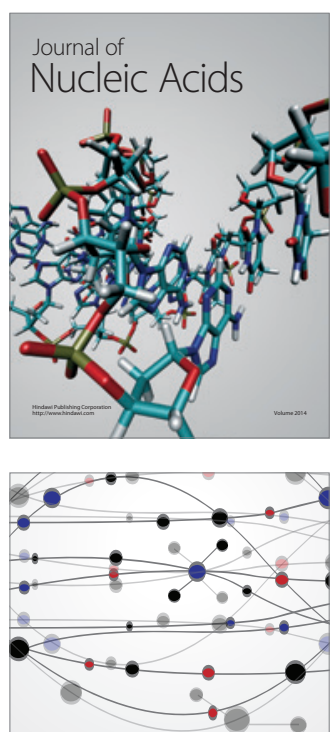

The Scientific World Journal
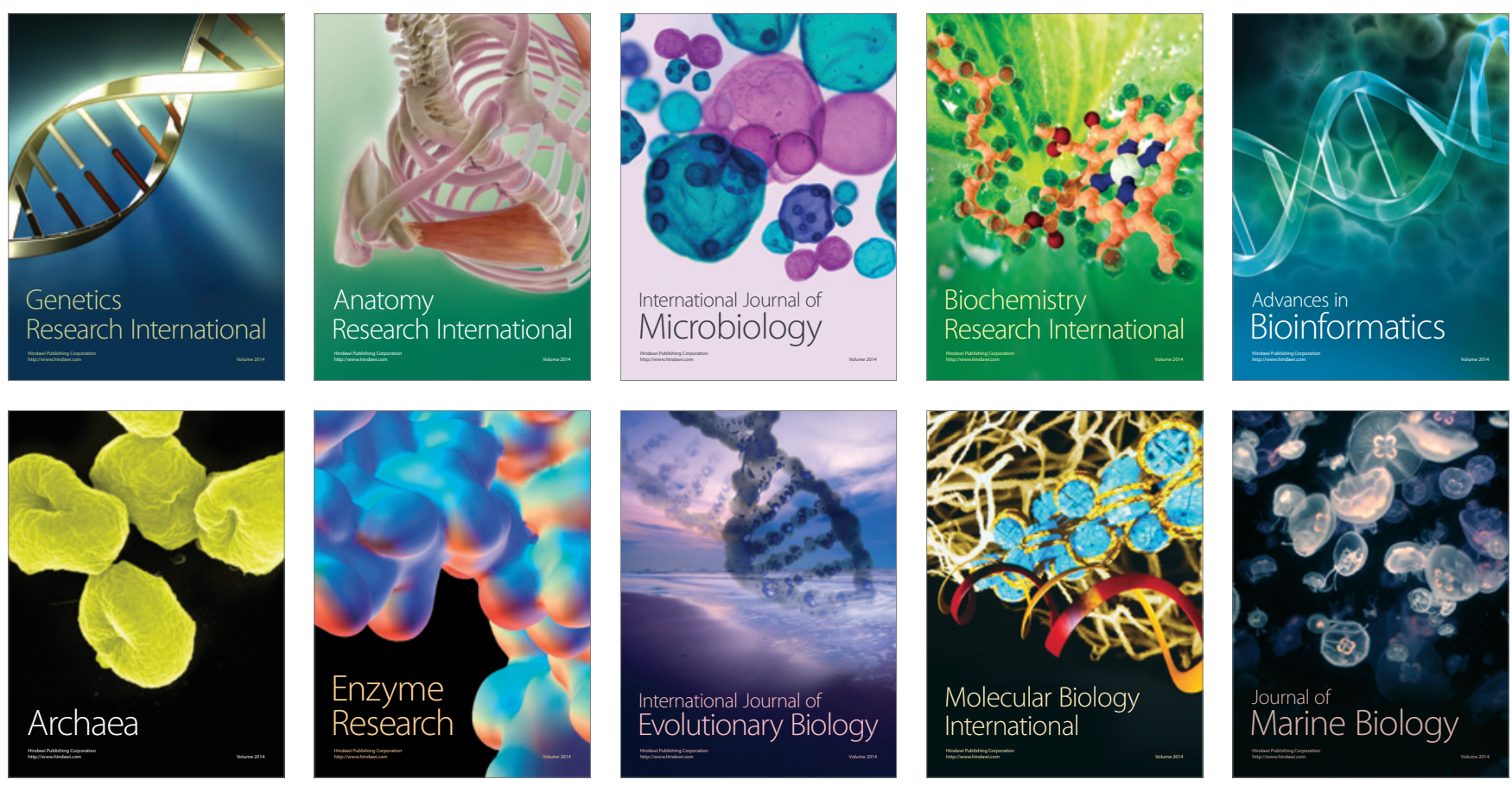